\title{
On the Development of Rotating Credit Associations in Japan
}

\author{
Working Paper No. 168 \\ Robert Dekle \\ Department of Economics \\ University of Southern California \\ Los Angeles, CA 90089
}

\author{
Koichi Hamada \\ Department of Economics \\ 27 Hillhouse Avenue \\ Yale University \\ New Haven, CT 06520-8269
}

September 1999

*Corresponding author.

This paper was made possible through support provided by the U.S. Agency for International Development under Cooperative Agreement No. DHR-0015-A-00-0031-00 to the Center on Institutional Reform and the Informal Sector (IRIS) and administered by the Office of Economic and Institutional Reform, Center for Economic Growth, Bureau for Global Programs, Field Support and Research.

Research for this paper has been supported by a grant from IRIS at the University of Maryland at College Park. The authors thank Christopher Clague, seminar participants at Yale University, an 


\section{Introduction}

Economic growth raises income and wealth and promotes financial intermediation. On the other hand, financial intermediation facilitates economic growth, since better financial intermediation raises the returns to investment.

In the process of economic growth, many informal financial schemes are incorporated into a more formal, well organized, national financial system. One of the central problems of economic development is how to tap the saving of the households in the informal and rural sectors to finance industrial development (Myint, 1964, p.128; McKinnon, 1973). Thus, there is continued, intense interest in the design of financial institutions that can attract the accumulated wealth of the small, rural saver.

In this paper we will study the development of an important informal financial intermediary in Japan, the rotating savings and credit association (RoSCA) called the Mujin (kō) or the Tanomoshi-ko. Mujins have survived until today (in the form of "Second-Tier" regional banks) from the traditional, pre-Modern era. That they have survived from the pre-Modern period suggests that these institutions may serve an economically useful purpose. As we will show later, although small, Mujins have traditionally provided funds to small- and medium-sized firms in the local sectors of the Japanese economy. In 1915, the Japanese Ministry of Finance first passed laws to regulate the Mujin. Soon after World War II, the government reorganized the Mujins as mutual (Sogo) banks, and the banks started accepting deposits. Only a few years ago, these mutual banks were reorganized into the so-called "Second-Tier" regional banks. ${ }^{1}$ In the early 1990 s, these regional banks were

\footnotetext{
${ }^{1}$ There are today over 50 "Second-Tier" regional banks in Japan, but they hold less than 10 percent of total deposits.
} 
especially hard-hit by the bad loan problems arising from the burst of Japan's asset price bubble.

RoSCAs are found all over the world, and much has been written about them (Bouman, 1977; Geertz, 1962; Campbell and Ahn, 1962). The features of Japan's Mujins have much in common with those in other parts of the globe. There are several reasons why a study of the Japanese Mujins may be of interest. First, few accounts of Japan's RoSCAs exist in the English language, in contrast to the fact that RoSCAs in many other countries including Korea and Taiwan are well-documented in English (Besley and Levenson, 1996). Second, an analysis of the Mujin is important because of its interesting financial mechanism and of its role in everyday finance in preModern and post-Restoration Japan. Third, the process of transforming the Mujin into a modern corporate form is interesting from both economic and political perspectives. From the political perspective, the Ministry of Finance (MOF), assisted by the Bank of Japan, took the initiative and successfully attained its bureaucratic objective of incorporating the Mujin into the formal Japanese financial sector.

The policy implications of our history of the Mujin would be the following. As we show, the Mujins relied on monitoring mechanisms enforced by kinship, religions, and local community ties. As the Mujins became larger, more members of the Mujins were inevitably total strangers, and moral hazard problems increased. Thus, over time the Japanese Ministry of Finance increased its regulation of the Mujins.

The Ministry of Finance could be justified in trying to contain the Mujin institutions under its control and modernizing them, so that the common people would not suffer from dubious practices prevalent at these institutions. From 1930 to 1990 , there hardly were any Mujin bankruptcies. Thus, the Ministry of Finance's objectives were well achieved. Or, we can say that 
the objectives were too well achieved. For, one cause of the present financial turmoil in Japan has been that banks, including banks originated from the Mujin, have been excessively tamed by the banking regulations of the Ministry. These banks have become accustomed to relying on administrative guidance so much that they have lost their sense of initiative and independent responsibility for their financial decisions.

This paper is organized as follows. In Sections 2 to 4 , we describe the origins, the development, and the workings of the Mujin. In Section 5, we describe how the theory of RoSCAs can be applied to the Mujin. In Section 6, we provide some evidence that lower income people made more extensive use of the Mujin than higher income people. Section 7 concludes.

\section{Pre-Modern Origins of the Mujin}

The Mujin is a Japanese form of a rotating saving and credit association. Members of the Mujin contribute funds and can win the pot by drawing or by bidding. The Mujin originated from Buddhist traditions, coming from India, China, and Korea, and finally to Japan. In Japanese historical records, the word "Mujin" first appeared in 1255, but at that time referred to pawn-shop financing. Later the word was used synonymously with Tanomoshi, which is Japanese for rotating savings and credit associations (RoSCA). ${ }^{2}$ By the Muromachi period (1338 - 1467), the institutional form of the Mujin=Tanomoshi-ko had been firmly established.

In Buddhist teachings, Mujin means inexhaustible, something like the widow's curse. Tanomoshi-ko means a trustworthy community. In principle, Tanomoshi provided financing without

${ }^{2}$ We owe the following descriptions to Zenkoku Sogo Ginko Kyokai (1971), Miyamoto and Takashima (1991) and Mori (1982). 
collateral and without interest payments. When commercial lenders did not provide sufficient lending to the poor, a group of people gathered, contributed a certain sum of money, and extended loans to the needy. Even during Japan's pre-Modern period, these rotating savings and credit associations were considered to be helpful, even ingenious, schemes of financing.

The traditional system of the Mujin-Ko or Tanomoshi-Ko contract consisted of the following elements.

(1) Initiators or originators of Ko were called "Parents."

(2) The initiator gathered a few to more than ten people who constituted the membership of the Ko.

(3) The members agreed on the terms of the operation.

(4) Members attended regularly the meeting of the Ko and had to make a contribution of a certain amount of money.

(5) The money collected was paid out as a "pot" to a person determined by chance drawing or by bidding.

(6) In case the money was paid out by chance drawing, the members who obtained a pot could not participate in any additional drawing. The members were required to give contributions to the meeting each time. Some interest could be added.

(7) After everybody obtained a loan, the Ko would dissolve.

(8) The interest was adjusted so that late receivers of the pot contributed less in total than what they received in total, when interest payments from early borrowers are included.

The Tokugawa (Edo) period started in 1603 and more than two hundred fifty years of political stability followed. Temples and shrines organized the Mujin so that a person who had won the pot in an earlier round did not have to contribute afterwards. This arrangement made the Ko more like a gamble than a mutual-help financial organization. A person who won early could take the funds and leave. Even the central (Shogunate) and local (Daimyo) governments were tempted 
to hold Mujin-type raffles for the sake of raising revenues.

Some writers emphasize the use of the Ko for social welfare purposes. During the Kyo-ho (1716-36) reform, the poverty of farmers escalated. After the following famine and earthquake, Miura Baien opened the Charity-Mujin in 1756 which gave funds to members who had poor harvests. The timing of the distribution of the pot was set to meet the needs of the indigent. In fact, those who were faced with disaster often asked their friends to form a Mujin. The disaster victim would then be allowed to draw from the pot first. Thus, a significant element of charity was involved.

In 1868, the Tokugawa period ended, replaced by the Meiji Restoration, and a central government based on the Emperor's ultimate authority was established. The Restoration was characterized by relative political stability in spite of the great change in regime. Free trade was forcefully imposed by foreign countries, which facilitated Japan's rapid modernization. The land tax was introduced to secure the basic revenue for the government. The Japanese currency, the yen, was introduced in 1871. Banks, credit unions, and the Postal Saving System were all imported from the Western countries. The Mujin or the Tanomoshi was the only financial institution that had survived into the Meiji period from the old, traditional Japanese regime.

The Mujin remained virtually the only traditional financial institution carried over from the Tokugawa period. Despite the introduction of banks, savings and loans, and other modern financial institutions from the West, most ordinary people, and especially rural dwellers, did not used these modern institutions. Rather, the Mujins continued to be popular. Farmers formed Mujins to obtain funds to buy equipment. Craftsmen often formed Mujins among those in their trade. Many village dwellers formed Mujins, not for financing, but simply to provide an opportunity for social gathering 
and friendship. However, after the Meiji Restoration, there arose many informal, but commercial, groups that exploited the Mujin method, not for the sake of religious activities or mutual help but for the sake of profit.

In the early Meiji years, there emerged Mujin enterprises that were permanent in the sense that they did not dissolve after one cycle of the Mujin and were commercial in the sense that they were completely driven by profit motives. In particular, around the turn of the nineteenth century, numerous Mujin in the form of partnerships or joint-stock companies were established. For example, in 1901, Yamato Kai started with contributions by 150 members, 5 yen for every 20 days. This was called the Osaka type, which had less of an element of gambling.

These commercial Mujins were usually started by entrepreneurs. The Yamato Kai was started by Kankichi Kobayashi, who went on to start over 20 Mujins throughout Japan. Many of these Mujins differed considerably in style from the traditional Mujins. For example, in some of the new Mujins, not all members were allowed to draw from the pot. In extreme cases, none of the members could draw from the pot and all of the contributions were loaned, with interest, to the entrepreneur-originator of the Mujin. The only similarity that these new Mujins had with the traditional type was that members had to make contributions in regular intervals. Because of their increasingly commercial nature, starting from Hiroshima prefecture in 1898, many prefectures imposed regulations on the Mujin business.

\section{The Mujin Finance Law}

The Ministry of Finance (MOF) and The Bank of Japan made studies on the ongoing practices of the Mujin around 1915 and pointed out the advantages and the disadvantages of the 
Mujin. According to the Ministry of Finance, around that time there were 831 units that operated the Mujin, and their total capital amounted to 20.3 million yen. Of the 831 units, over 80 percent were incorporated as joint stock companies.

\section{Advantages of Mujin:}

(1) Low income people do not like new methods of financing that have been imported from Western countries.

(2) Pawn borrowing and shark borrowing are not what low income people prefer. These methods often charge prohibitive rates of interest.

(3) People do not have, however, psychological resistance to the Mujin, the traditional means of finance.

\section{Disadvantages of Mujin:}

(1) It is difficult to force those who obtain the pot at an early draw to make further contributions.

(2) There are occasions of unfair drawing.

(3) There are often unfair differences in the implicit interest rates.

(4) A very high rate of interest may emerge by bidding, which may make the Mujin usurious.

(5) The timing of lending is inflexible.

(6) The accounting procedure is nontransparent.

Some of the above alleged advantages and disadvantages of the Mujin lack sound economic foundations. For example, Besley, Coate, and Loury (1993) have shown that under a "bidding" type RoSCA, early acquirers of the pot bid more. These higher bids by earlier recipients resemble interest payments, and in this sense, a bidding RoSCA can be likened to a loan market. Moreover, Besley, Coate, and Loury (1993) have shown that with heterogeneous individuals, the 
higher bids can serve as a sorting mechanism, giving the pot to the individual with the highest valuation first. If a given individual greatly values receiving the pot early, the individual will bid high, and his implicit interest rate will be high. Thus, implicit interest rates will differ by bidder, and very high interest rates may emerge as an equilibrium outcome. Different and high interest rates may not necessarily be unfair.

Justified by economic foundations or not, the Meiji and later governments tried to strengthen the disadvantageous aspects and keep the advantageous aspects by making the Mujin a more modern institution. The Ministry of Finance drafted a regulatory act that prohibited dubious practices and modernized the accounting systems of the Mujin. Many Mujin companies strongly opposed the enactment of the Mujin-Gyo-Ho (Mujin Finance Law).

In 1915, the Mujin Finance Law passed the Diet and was soon implemented. The definition of the Mujin was clarified. The amount of the pot, the amount of the premium (contribution), the duration of the operation, and the number of members came under strict limits. For example, according to the attachment to the Law, a Mujin should not last more than 5 years, one unit of pot should be under 10,000 yen, and a company should not operate more than 100 groups. The most effective regulation in the Law was that the Mujin enterprise should be organized as a company, and that 15,000 yen should be paid in as capital.

It may appear odd that the government will impose a capital requirement on RoSCAs. After all, in a traditional RoSCA, the money collected each month is immediately disbursed to the members. The capital requirement makes the post-1915 Mujin fundamentally different from a "pure" RoSCa, in which funds are cleared each period. As mentioned, however, by 1915, most Japanese RoSCAs had become commercially-oriented. Some new Mujins were started by 
between savers and borrowers. Gradually, after the passing of the Mujin law, the Osaka style became more dominant. In 1939, all except three prefectures adopted the Osaka style.

In 1935, the MOF found that there were more than three thousand different schedules relating to the timing of the draw, and payments. The MOF attempted to unify these schedules at the prefecture level, but in 1939 there were still more than one thousand schedules.

The rate of return to participants in the Mujin is fairly complicated because such variables as the timing of the pot (kitty) payment, the auction price, contributions before the payment, and contributions after the payment all affect the returns.

For the purposes of standardizing the schedules, the MOF provided formulas for calculating the internal rates of interest. For the lottery type or "random" RoSCA of the Osaka style, let us introduce the following notation:

Payment of the pot: A

contributions before the payment: B

additional contributions (over B) after the payment: $\mathrm{B}^{\prime}$

the total number of periods: $m$ (the number of periods at which the Mujin contract ends).

the timing of the payment: $n$

the interest rate on bank deposits: i

the implicit rate of borrowing: $r$.

The implicit, effective rate of borrowing, $r$, was calculated by equating the present values of the payment and that of the contributions calculated at the end of the Mujin contract (Zenkoku Sogo Ginko Kyokai, 1970), period m. (Campbell and Ahn calculate similar implicit rates of interest 
entrepreneurs to fund their other businesses. These entrepreneurs discovered that funds can be raised more easily if their new financial organs resembled more traditional financial institutions, familiar to the common people. Thus, these organs adopted the monthly contributions scheme of the traditional Mujin. However, drawings were not allowed or were limited to a few insiders. Other new Mujins essentially operated like the traditional Mujins, but had professional entrepreneurmanagers who collected administrative/management fees from the members. Thus, by 1915 , most Mujins operated differently from a pure RoSCA.

The capital requirement in effect served as a "bond" to make the entrepreneur operate the Mujins more honestly and efficiently.

The Mujin finance law made withdrawing from the Mujin more systematic. Traditionally, early withdrawal caused problems for the Mujin, since a fall in membership meant that suppliers of funds became more scarce. According to the new law, one could only withdraw if appropriate successors were found.

In the traditional Mujin, there were two ways of calculating contributions and payments from the pot, the Tokyo and Osaka styles. In both styles, the pot was distributed each period by lottery. The Tokyo style was the method that kept the contributions unchanged before and after the period when the participant received the payment. The Osaka style was the method that increased the amount of contributions after the period when the participant received the payment. Since an earlier pot payment meant an economic advantage for the member, the Tokyo style involved the element of luck or gambling. In contrast, in the Osaka style, an earlier pot payment was not necessarily advantageous, because the recipient had to pay higher contributions for a longer period. Thus, the Osaka style was closer in spirit to the traditional role of financial intermediaries, transferring funds 
for Kye or Mujins in Korea.)

$$
A(1+r)^{m-n}=B \sum_{t=1}^{m}(1+i)^{t}+B^{\prime} \sum_{t=n}^{m}(1+i)^{t} .
$$

If one neglects the second order terms, one obtains,

$$
A\{1+(m-n)\} r=B\left\{m+\frac{m(m+1)}{2} i\right\}+B /\left\{(m-n)+\frac{(m-n)(m-n+1)}{2} i\right\}
$$

or,

$$
A(m-n) r=B m+B^{\prime}(m-n)-A+i\left\{B \frac{m(m+1)}{2}+B^{\prime} \frac{(m-n)(m-n+1)}{2}\right\} .
$$

and therefore,

$$
r=\frac{B m+B^{\prime}(m-n)-A+i\left\{B \frac{m(m+1)}{2}+B^{\prime} \frac{(m-n)(m-n+1)}{2}\right\}}{A(m-n)}
$$

where $B m+B^{\prime}(m-n)$ is the total premium, the term in the \{\} bracket is the number of months of premium payments, and $A(m-n)$ is the length of borrowing. Therefore, the effective rate of borrowing or receiving $\mathrm{A}$ is given by:

$$
\begin{aligned}
& \begin{array}{l}
\mathrm{r}=\text { Total Premium }- \text { Amount of }+(\text { Accumulated Months } \\
\text { Payments }
\end{array} \text { the Pot Bank Deposit } \\
& \text { Length of Borrowing }
\end{aligned}
$$


In order to determine whether participating in the Mujin is more profitable than making a bank deposit, the $r$ above should be compared to the bank deposit interest rate, $\mathrm{i}$, the opportunity cost of funds. The problem for a Mujin participant is of course that he does not know n, the time when he obtains the pot. $\mathrm{r}$ is therefore uncertain ex ante. ${ }^{3}$

The influence of the MOF was not limited to the unification of contribution-payment schedules and interest rates. The Ministry of Finance also played an important role in consolidating the numerous Mujins.

After the passing of the Mujin Finance Law, the number of Mujins fell from 2363 to only 136. In 1915, the Mujin came under the control of the Ministry of Finance. In 1931, the MujinFinance Law was amended, and the Mujin was permitted to exist only as joint stock companies.

After the financial crisis of 1927 , and consequent financial bank-runs, the Ministry of Finance tightened its control and tried to limit the number of banks and Mujin companies. During the Second World War, the Ministry of Finance attempted to reduce the number of Mujin to one in each prefecture, to 47. Sometimes Mujin companies were hesitant to be merged, but the MOF argued that mergers were necessary to increase the efficiency of the banking system, and that banking efficiency was necessary to win the war against the United States. During the war period, an important concern of the government was to increase saving rates. Thus, although deposits were

\footnotetext{
${ }^{3}$ However, given that each participant knows the number of group members and the length of the RoSCA, $m$, each participant can form an expectation of $\mathrm{n}$. For example, in a RoSCA of three players lasting three periods, the expected value of $\mathrm{n}$ is 2 . Thus, given expected $n$, the expected real interest rate can be calculated. See Besley, Coate, and Loury (1994) for a more general exposition.
} 
not allowed de jure for Mujin companies, by various devices it was made possible for the Mujin to de facto accept saving deposits.

\section{Post-war Development of the Mujin.}

After the Second World War, Japan's economy and financial markets were in turmoil. There emerged many small finance companies (called shokusan kaisha, meaning "industry promoting companies") that provided funds to small and medium-sized companies. After paying-in deposits of at least 50 yen for 60 times, a client could obtain 10,000 yen in credit. These finance companies differed from the Mujin in that a group did not need to be organized, and borrowing was possible without lotteries or auctions. The financing conducted by these schemes was called Minashi (bogus) Mujin. These "bogus" Mujin soon became very popular, and the government amended the MujinFinance law to include these new finance companies. The passing of this amendment started the transformation of the Mujins from their original form as a rotating credit association to more general financial intermediaries.

Officials at the General Head Quarters (GHQ: the popular name of the Supreme Commander

of Allied Forces that was occupying Japan after World War II) were not sympathetic to Mujin operations, and prevented Mujins from accepting demand deposits. GHQ officials did not understand Mujins well, and regarded them not as a means of finance, but as a means of gambling. GHQ officials wanted to limit deposit activities to only commercial banks, which was the situation in the United States (Zenkoku Sogo Ginko Kyokai, pp.147-8).

In practice, however, the post-war Mujins played an important role in providing finance for small and medium-sized enterprises. However, as the Japanese economy developed, some of the 
provisions of the post-war Mujin Law became too restrictive. For example, lending was usually limited to within a prefecture, and there were strict limits placed on where excess funds could be invested.

The National Mujin Association therefore asked the government to draft a new law that would make the Mujin companies more like small-scale banks. Small and medium-sized enterprises were also dissatisfied with the loan behavior of the large banks, and needed banks that dealt more exclusively with small- and medium-sized firms. To appease the GHQ, the name Sogo Ginko or "mutual banks" was chosen to refer to the transformed Mujins. The Sogo Ginko Ho, or Mutual Bank Act passed the Diet on May 1951. Most Mujins were converted to Sogo banks in 1956. However, informal Mujins have continued to operate in Japan. These informal Mujins meet regularly among 10 to 30 people and appear to serve an important social function. For example, even in the late 1990s, over several hundred informal Mujins operated in the Aizu region.

The purpose of the Mutual Bank Act was to "provide smooth financing to the (common) people and to promote the savings of the (common) people (Article 1)." The activities of the Mutual Banks included among others (i) accepting premiums or contributions with a contract to pay during or at the end of the contract --- the essence of the traditional Mujin business; (ii) accepting deposits or term deposits; and (iii) extending loans and discounting bills. Items (ii) and (iii) were activities that had only been partially allowed previously. There were still, however, size and geographic restrictions on loans.

It is usually believed that the Japanese government is so strong that it can realize whatever it intends to accomplish. During the Second World War, most of the attempts by the MOF to consolidate the Mujins were realized. After the war, however, there were some cases where merger 
attempts were unsuccessful.

For example, in 1978, the executive directors of Kansai Sogin in Osaka voted to merge with the gigantic Sumitomo (commercial) Bank, which already had sent six executives (among the total eleven) to Kansai Sogin. The MOF encouraged the move as a way of achieving efficiency in the banking sector. However, labor unions, branch chief managers, and, moreover, clients of Kansai Sogin strongly opposed the merger. A description of their grounds for opposition is worth recording.

"--- I doubt if banks should follow solely the objective of efficiency. The effect on clients should be taken into account as well. --- There is a difference of philosophy between Sumitomo and us. Sumitomo is an institution in which a handful elites take leadership and everybody else pursues the same target in perfect order. They live an admirable life, ---, but as a human, a uniform, stereotyped life. --- We are different. We have been helping management of small and medium enterprises. Our job is hard, not so fashionable, but we are proud of it." (Goto 1994, p.453)."

Because of this strong opposition, the Chairman of the National Association of Mutual Banks opposed the merger and asked the MOF to settle the situation. It was the first time that the Association expressed an opinion on the management policies of an individual participating bank. The MOF took the side of the opposition, and the merger failed.

Since the 1980s, mutual bank mergers were the general trend. Moreover, the transformation of the mutual banks into commercial banks was made an important agenda of the government. After thirty years of the mutual banking system, the mutual banks in the 1980 s performed about the same general activities as the general commercial banks. In 1985, the Kinyu Seido Chosakai (Advisory Study Council of the Financial System) changed its attitude from keeping the status quo in the banking sector to advocating the transformation of the mutual banks into commercial banks. Thus, 
between 1989 and 1990, all of the mutual banks were transformed into commercial banks.

\section{The Theory of Rotating-Credit Associations.}

An interesting theoretical question is why the Mujins were sustainable as a method of finance. What types of economic incentive mechanisms were working in the Mujins, or more generally, in rotating Savings and Credit Associations (RoSCA)? A rigorous study of economic incentives is given in Besley, Coate and Loury $(1993,1994)$. In their model, Besley, Coate, and Loury $(1993,1994)$ or BCL, emphasize the following aspects of the RoSCA.

First, their model predicts that RoSCAs are likely to be small in membership, and their members, socially connected. Since those who receive the pot early are effectively in debt to the other group members, individuals have an incentive to refuse to honor their membership commitment after winning the pot. By forming a RoSCA among a small group of socially connected individuals, say among individuals from the same village or occupational guild, these individuals are likely to have good information about the reliability of their neighbors and co-workers and can enforce sanctions-social and economic-on those who are delinquent without good reason. A corrollary is that some limit on the number of members may be socially desirable. In larger groups, it becomes more difficult to keep track of defecting members. BCL show that this effect is likely to outweigh the intermediation benefits of a larger membership in groups above a certain size.

Second, their model predicts that RoSCAs are in general, less efficient than credit markets. Thus, the development of credit markets would most likely weaken the institution of the RoSCA over time, especially if the credit markets are available to all segments of the population.

Third, their model predicts that RoSCA winnings will be mainly used for the purchases of 
indivisible durable goods. ${ }^{4}$ The RoSCAs provide a rule for rationing access to the indivisible good: random allocation in a "random" RoSCA and bidding in a "bidding" RoSCA. Thus, the BCL model surprisingly predicts that the average RoSCA member is likely to be richer than the average population. This is because in developing countries, durable goods purchases are richer than the average population.

In sum, in their mathematical formulation of RoSCAs, Besley, Coate and Loury (1993) show that the RoSCA is a desirable device for a group that is socially connected, and that the RoSCA improves upon autarky savings of those who do not have access to any other capital market.

The Mujins share many features with the BCL model. Most traditional Mujins were of the random type, and proceeds from the draws were used to fund significant, idiosyncratic expenses such as new farming equipment, start-up funds for businesses, and weddings. Initially, members of the Mujin were socially connected. Mujin members were often from the same village, craft, or workplace. However, as the Mujins became more commercially oriented, the Mujins expanded their membership, and increasingly, members were strangers. Thus, consistent with the first prediction of the BCL model, enforcement problems arose, and some individuals did not keep their

${ }^{4}$ Calomiris and Rajaraman (1998) take issue with BCLs prediction that RoSCA participants are mostly those saving for nondivisible durable goods. Calomiris and Rajaraman argue that the actual operations of most real-world RoSCAs do not conform to BCLs typified example in which members bid for the pot at the time the RoSCAs are formed. In fact, in most real-world RoSCAs, members bid concurrently with the drawings. Calomiris and Rajaraman argue that the durable goods saving motive cannot explain the fact that actual allocations received by participants are subject to ex post variation via the bidding process; the ex post variation in the allocations suggest an important insurance feature of the RoSCAs. In contrast to BCL, Calomiris and Rajaraman add that evidence of RoSCA participation by the poor in developing countries is very widespread. This is because the potential insurance function of the RoSCAs tends to be the most important for the poor, who are over-represented in occupations with large uninsurable wealth shocks. 
commitment to pay into the RoSCA after they had won the pot. The Japanese Ministry of Finance recognized the difficulty in forcing those who obtained the pot at an early draw to make further contributions, and in the 1915 law placed strict limits on the number of Mujin members.

We also showed that as the common people gained access to the banking system through the Sogo banks, the Mujins declined in popularity, although they were not outlawed. This is consistent with BCLs second prediction taht the development of credit markets will weaken the RoSCA.

\section{Mujin Use by Low Income People.}

The third prediction of the BCL model is that the average RoSCA member is likely to be richer than the average population. Levenson and Besley (1996) present evidence for Taiwan that higher income households are more likely to use RoSCAs, thus supporting the BCL model. To date, Levenson and Besley offer the only systematic evidence of RoSCA use. Such systematic evidence is not available for Japan prior to the Mujins' conversion to Sogo banks in 1956. However, fragmented evidence suggests that in Japan, Mujins were used more extensively by lower income households.

Immediately before the Mujins conversion to Sogo banks, there was a survey taken of Mujin activities. The survey found that of the total savings of Japanese households in 1950,65 percent were in banks, 15 percent were in postal savings, 10 percent were in agricultural cooperatives, and 6 percent were in Mujins. The average "deposits" (contributions minus payments) per person in the Mujin were 3183 yen compared to over 10 times that amount per depositor for banks. Thus, it appears that on average, Mujin "deposits" were much smaller than bank deposits.

Since the mid-1960s, surveys have been taken of the Japanese households' saving behavior. 
The survey of 1967 (Family Saving Survey) found that of the households in the top quartile of earnings, 66 percent and 4.8 percent had savings in banks and in the Mujins, respectively. ${ }^{5}$ Of the households in the middle 50 percent of earnings, 46.3 percent and 7.3 percent had savings in banks and in the Mujins, respectively. Of the households in the bottom quartile, 31.7 percent and 16 percent had savings in banks and in the Mujins, respectively. Thus, households with lower income tend to use the Mujin more extensively than households with higher income.

That the average participant in the Mujin was relatively poor suggests that the Mujin may also have been used for purposes other than saving for durable goods, such as for insurance. In fact, we have shown that originally, Mujins were formed to provide charity to the unfortunate.

\section{Concluding Comments.}

An interesting international aspect of Japan's Mujin is its propagation in Korea and Taiwan. Korea has its own RoSCA called Kye. Campbell and Ahn (1962) document the existence of the Kye in Korea. Kyes gained popularity after the Korean War. According to them "in June 1959, --- out of 2,691 households sampled, 1,603 were liable for debts. Approximately eight percent of the borrowers obtained their loans from banks. The bulk of the borrowers obtained their loans from 'individuals and acquaintances'." Campbell and Ahn interpret the last category as consisting of loans through Kyes. Besley and Levenson (1996) document the existence of RoSCAs in Taiwan called the hui.

Most of the features of the RoSCAs that are found abroad can be found in the Japanese

\footnotetext{
${ }^{5}$ Recall that Mujins have continued to exist informally, even after the passage of the Mutual Bank Act in 1951.
} 
versions. By tracing the history of the Mujin (Tanomoshi) for more than 700 years, we have observed many facets of the evolution of financial intermediation at the informal level, the function of contingent contract in financial transactions under incomplete information, and the role of the government in the formation of the modern financial system. The Japanese government has attempted to consolidate, rationalize, and economize the activities of the Mujin. After the Mujin-gyo Ho (the Mutual Bank Act) was enacted, Mujin companies and mutual banks were forcefully merged and integrated.

Mujin is a form of traditional finance that combines skillfully the capacity to monitor the availability of funds. To cope with indivisibilities of investment and to cope with monitoring problems, this system has developed and survived as a surprisingly popular financing system, in spite of the simultaneous development of modern financial institutions.

At first, elements of religion and charity were strong. The information problems of monitoring borrowers was alleviated by mutual surveillance within the group; as common members of the same Buddhist sect, members could usually trust each other. However, the traditional Mujin was limited because the group had to be homogeneous. As the Mujin expanded to include a larger number of people, the profit motive and the possibility of fraud entered. 


\section{REFERENCES}

Asakura, K. (1988) Japanese Financial History (Nihon Kinyu Shi) Nihon Keizai Hyoron Sha.

Banerjee, A., T. Besley and T. Guinnane (1994) "Thy Neighbor's Keeper: The Design of a Credit Cooperative, with Theory and Evidence," Quarterly Journal of Economics.

Bank of Japan, Research Bureau (1913) Mujin Kaisha ni Kansuru Chosa (A Survey of Mujin Companies) Tokyo.

Besley, T., S. Coate and G. Loury (1993) "The Economics of Rotating Savings and Credit Associations," The American Economic Review, Vol. 83, No. 4, pp. 792-810, September 1993.

Besley, T., S. Coate, and G. Loury (1994) "Rotating Savings and Credit Associations, Credit Markets and Efficiency,” Review of Economic Studies, Vol. 61, pp. 701-19.

Besley, T. and A. Levenson, (1996) "The Role of Informal Finance in Household Capital Accumulation: Evidence from Taiwan," Economic Journal, Vol. 106, pp. 39-59.

Bouman, Fritz J. A. (1977) "Indigenous Savings and Credit Societies in the Third World: A Message" Savings and Development, 1977, 1(4), pp. 181-218.

Calomiris, C., and I. Rajaraman, (1998) "The Role of ROSCAs: Lumpy Durables or Event Insurance," Journal of Development Economics, Vol. 56, pp. 207-16.

Calder, K. (1994). Strategic Capitalism. Princeton: Princeton University Press.

Campbell, C. D. and C. S. Ahn (1962) "Kyes and Mujins - Financial Intermediaries in South Korea," Economic Development and Cultural Change, pp. 55-68.

Emi, K., M. Ito, and H. Eguchi (1988) Savings and Currency (Chochiku to Tsuka), Toyo Keizai.

Geertz, C. (1962) "The Rotating Credit Association: A 'Middle Rung' in Development," Economic Development and Cultural Change, April, pp. 241-263.

Goto, Shin-ichi (1971), "Zoku Nihon no Kinyu Tokei (Japan's Financial Statistics)" (1-4) Kinyu (Finance) Zenkoku Ginko Kyokai, July-October.

Goto, Shin-ichi (1994) Mujin-Sogin Godo no Jisshoteki Kenkyu (An Empirical Study of Mergers of Mujin and Mutual Banks), Nihon Kinyu Tsushinsha.

Hamada, K. (1993) "The Showa Confusion and the Heisei Recession," (Showa Kyoran to Heisei Fukyo), Toyo Keizai. 
Japan Development Bank (1993). Policy-Based Finance, The Experience of Post-war Japan, Economic Research Institute.

Kakinuma, S. And M. Nakamura (1994). "Japan's National Mega-Bank Also Sells Stamps," Tokyo Business, September.

Keynes (1936). The General Theory, Macmillan.

Levenson, A. and T. Besley (1996) "The Anatomy of an Informal Financial Market: Rosca

51, pp. 45-68.

Participation in Taiwan," Journal of Development Economics, Vol.

Lewin, W. (1866). A History of Banks for Savings. London: Sampson, Low, and Marston.

McKinnon, R. (1973) Money and Capital in Economic Development, Washington, DC, The Brookings Institution.

Miyamoto, M. and Takashima, M. (1991) The Financial History of the People, (Shomin no Ayunda Kinyu Shi), Osaka: Fukutoku.

Mori, K. (1982) Mujin Kinyu-shi Ron (The Collected Work of K. Mori, Vol. 2), Tokyo, Hosei University Press.

Morishima, M. (1982) Why Has Japan 'Succeeded'? Western Technology and the Japanese Ethos, Cambridge, MA, Cambridge University Press.

Myint, H. (1964) The Economics of the Developing Countries, New York: Praeger.

Patrick (1966) “Japan, 1868-1914," in Rondo Cameron, ed., Financing in Economic Development, Oxford.

Stiglitz, J. (1990) "Peer Monitoring and Credit Markets," World Bank Economic Review.

Stiglitz, J. (1993). “The Role of the State in Financial Markets,' Proceedings of the World Bank Annual Conference on Development Economics.

Stiglitz, J. and Andrew Weiss (1981) "Credit Rationing in Markets with Imperfect Information," American Economic Review.

Teranishi, J. (1982) Japanese Economic Development and Finance, Tokyo,Iwanami.

Townsend, R. M. (1992) "Understanding the Structure of Village and Regional Economies" in L. Werin and H. Wijkander, eds., Contract Economics, Blackwell. 
Townsend, R.M. (1994). "Risk and Insurance in Village

India,"Econometrica, 62(3).

Zenkoku Sogo Ginko Kyokai, (1971) Sogo Ginko Shi, (The History of Mutual Banks) Tokyo. 